\title{
Commitment of the Elderly People in Bulgaria to their Own Health
}

\author{
Silviya Kyuchukova*, Albena Andonova, Mima Nikolova, Mariana Penkova-Raditcheva \\ Department of Health Care, Trakia University, Medicine Facultacity, Stara Zagora, Bulgaria
}

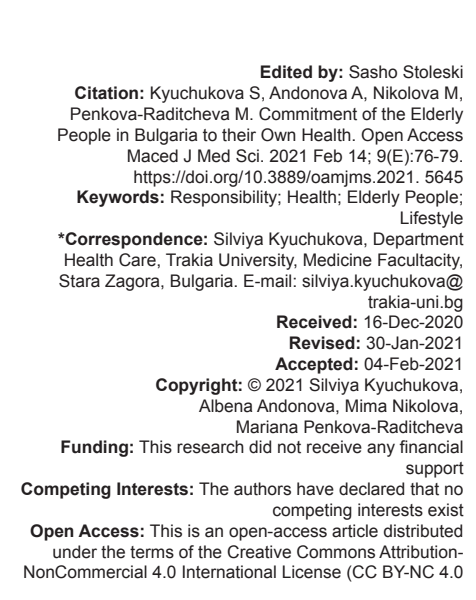

Abstract

BACKGROUND: In the context of health education, the lifestyle of each individual includes social and behaviora factors that are potentially manageable and preventable in general. A health-educated person adheres to healthy lifestyle, which is characterized by the presence of: active attitude to his own health, positive health motivation, skills for health protection and strengthening, and useful health habits. Stimulating one of them is the systematic monitoring and registration of the main vital indicators, as a good prerequisite for active monitoring of the health condition. As of December 31, 2019 the population of Bulgaria is 6,951,482 people, and the people, aged 65 and over are $1,504,088$, or $21.6 \%$ of the country's population.

AIM: The objective of this study was to establish the degree of personal commitment and responsibility for their health of people over 65-year-old, living in Bulgaria. Tasks: (a) To make a questionnaire, (b) Processing of the received information and analysis of results, (c) Formulation of conclusions regarding awareness, health motivation and lifestyle of the respondents, (d) Reporting the degree of responsibility for their health of the respondents.

METHODS: Mathematical-statistical - dispersion, comparative analysis, Spearman's rank correlation coefficient/ p/;desk research; interview. Contingent: 113 people; average age - approx. $68.168 \pm 8.80$ years. Time: 2019.

RESULTS: (1)A statistically significant relationship was found: $p=0.001$ and $x^{2}=21.886$. The respondents with two chronic diseases $-40.5 \%$ are well aware of the normal values of the measured indicators. (2) Two thirds of the respondents/74.3\%/ are well informed about the normal and pathological values of the main vital indicators, which they can measure and register themselves. (3) $76 \%$ of the respondents have received the necessary health information from the medical team/partnership model. (4) Only half of the older respondents in the study/51.4\%/follow a diet complied with their health status.

CONCLUSION: In our professional medical care for the elderly people in Bulgaria, we must place emphasis on their preventive and prophylactic commitment to their own health. The useful and practical combination of properly received and internalized medical information from the elderly people is an important prerequisite for their informed commitment to their own health.

\section{Introduction}

As of December 31, 2019, the population of Bulgaria was $6,951,482$ people, which represented $1.4 \%$ of the population of the European Union. Compared to 2018 , the population of the country decreased by 48,557 people, or by $0.7 \%$. There were $3,369,646$ men $(48.5 \%)$ and $3,581,836$ women $(51.5 \%)$, or 1063 women per 1000 men. The number of men predominated at the age of 53. Increasing the age, the number and relative share of women in the total population of the country is increasing, too.

The aging process of the population continues. At the end of 2019, the number of people aged 65 and over was $1,504,088$, or $21.6 \%$ of the country's population. Compared to 2018, the share of the population in this age group increased by $0.3 \%$. The aging process is more pronounced among women than among men. The relative share of women over the age of 65 is $25.1 \%$, and of men $-17.9 \%$. This difference is due to the higher mortality among men and, as a consequence, to the lower life expectancy among them.
In general, for the European Union, the relative share of population aged 65 and over is $20.0 \%$. This share is the highest in Italy $(22.8 \%)$, followed by Greece (22.0\%), Portugal, and Finland (21.8\% each). Totally, in nine countries, including Bulgaria, the share of the elderly population is over $20.0 \%$ [1], [2].

Modern and contemporary concepts and strategies for health protection and promotion replace medical determinism as an integrated approach. This requires replacement in the traditional notion that health of the population is solely in hands of doctors and other medical professionals. The Ottawa Charter from 1986, and the Jakarta Declaration from 1997, set out basic and additional principles and provisions that are fundamental to achieving good health. They emphasize the expansion of the partnership for health and increase the opportunities of the individual and society to achieve better health. The main emphasis and important principle in the Ottawa Charter is: Increasing personal responsibility and developing personal skills, knowledge, and opportunities for strengthening individual and public health [3], [4].

Some of the ways and means for solving these tasks are: autonomous decision making; model of 
partnership in the medical team-patient relationship as part of health education based on active communication, built on trust; and maintaining the health status of each individual through his personal commitment and responsibility.

Related to health promotion, the personality with his/her health culture and individual health behavior are considered a major resource of health. In this aspect, personal and collective responsibility for health is growing sharply.

Health beliefs/belief in the verification of a statement or the actual existence of a phenomenon/and relationships/are influenced by the beliefs and values of the individual and can reflect on feelings and behavior/health can be influenced by such factors as: Trust and respect to the one who sends the "message". They are relatively stable, but not fixed, they change and can be changed. They are acquired through the individual experience of family and friends, school and colleagues, and the media. They allow a person to select and rearrange their experience by expressing certain attitudes, to draw the attention of others, etc. They can be changed by imparting knowledge, on the grounds of value or by modifying behavior through influencing motivation. Maintaining the human psychoemotional status and physical activity is especially important for the elderly people [5]. Physical activity in elderly people is a factor helping to achieve better health and quality of life in various diseases [6], [7], [8].

The motivation of human behavior (moveo "move" in Latin) is defined as internal motives for induced action. Moreover, motives are set of psychological processes that activate human behavior, direct it to a specific goal and keep it steady over time. According to Maslow's model, the motivation is based on human needs, which he divides into five levels - basic, security, belonging, ego-status, and self-realization.

In the context of health education, the lifestyle of each individual includes social and behavioral factors that are potentially manageable and preventable in general. A health-educated person adheres to healthy lifestyle, which is characterized by the presence of active attitude to his own health, positive health motivation, skills for health protection, and strengthening, useful health habits. Stimulating one of them is the systematic monitoring and registration of the main vital indicators, as a good prerequisite for active monitoring of the health condition. This drew the attention of our research team to the goal and implementation of Research Project $N^{\circ} 13 / 2018$ at the Thracian University - Stara Zagora, Bulgaria, entitled: - Optimizing the care of the elderly people at home by introducing "Diary for tracking and self-monitoring of the condition."

\section{Objective}

The objective of this study was to establish the degree of personal commitment and responsibility for their health of people over 65-year-old, living in Bulgaria.

\section{Tasks}

- $\quad$ To make a questionnaire

- $\quad$ Processing of the received information and analysis of results

Formulation of conclusions regarding awareness, health motivation and lifestyle of the respondents

- $\quad$ Reporting the degree of responsibility for their health of the respondents.

\section{Methods}

Mathematical-statistical - $\quad$ dispersion, comparative analysis, Spearman's rank correlation coefficient/p/; desk research; and interview.

\section{Contingent}

113 people; average age - approximately $68.168 \pm 8.80$ years.

\section{Time}

2019.

\section{Conclusions}

- $\quad$ A statistically significant relationship was found $p=0.001$ and $x^{2}=21.886$. The respondents with two chronic diseases $-40.5 \%$ are well aware of the normal values of the measured indicators Two-thirds of the respondents/74.3\%/are well informed about the normal and pathological values of the main vital indicators, in which they can measure and register themselves

- $\quad 76 \%$ of the respondents have received the necessary health information from the medical team/partnership model

Only half of the older respondents in the study $/ 51.4 \% /$ follow a diet complied with their health status.

To achieve the goal, to perform the tasks set and to collect primary information, a questionnaire was created containing 22 questions, conditionally grouped as follows: identification data/gender, age, place of residence, social status, health status, etc./; personal assessment/self-assessment of health, 
chronic diseases, disability degree, medication, etc./; health literacy/knowledge of indicators, normal values, registration, actions in case of deviations, interaction with the medical team, etc.

Question 13 of the questionnaire reads: Do you know the normal values of the indicators you measure?

Table 1 two thirds of the respondents/74.3\%/ know these values, $15 \%$ also have some information that is incomplete and answer with "not all of them." To some extent, this gives us reason to assign these respondents to the first group. Only $10 \%$ of the respondents do not know the norms in the indicators they measure.

Table 1: Chi-square test

\begin{tabular}{llll}
\hline $\begin{array}{l}\text { Statistical } \\
\text { Indicators }\end{array}$ & Value & $\mathrm{dt}$ & Asymp, Sig. /2-sided \\
\hline Pearson Chi-square & $21.886^{\mathrm{a}}$ & 6 & 0.001 \\
$\begin{array}{l}\text { Likelihood ratio } \\
\mathrm{n} \text { of valid cases }\end{array}$ & 30.240 & 6 & 0.000 \\
\hline a6 cells $/ 50 \%$ / have expected count $<5$. The minimum expected count is 85 &
\end{tabular}

Looking for connection between the knowledge of the normal values of the basic vital indicators by the patients and the level of their awareness/questions 8 and 13, we found that there is direct relation. The respondents are well informed about the measures and care for their own health due to the professional attitude and behavior of the medical teams. Of $74.3 \%$ mentioned above, who know the normal values of the indicators that they measure, $76.2 \%$ have learned this from the medical teams caring for them, that is, they are good and reliable source of authentic information related to patients' health.

Knowing, registering and correctly interpreting basic vital indicators are important skills for elderly people, allowing them to control their health and to be independent. At the same time, the opportunity to ensure proper nutrition and adherence to a diet allows them to feel complete and to have full life.

Nutrition-related topics are becoming more relevant and debatable nowadays when the market is oversaturated with food supply and talking about it is becoming more modern. However, the issues related to the proper and healthy nutrition of people at the age defined as old age, require much attention and professional approach [9], [10], [11]. The right balance in the intake of proteins, carbohydrates, and fats is extremely important for the elderly people because age changes and many diseases put their body in challenge to cope with. Properly prepared and individually recommended, diet and nutrition are desirable to be followed by the elderly people to achieve better quality of life. Do they do this? - This question makes us ask the same in the questionnaire, namely:

Do you follow a diet, related to some of your diseases? Unfortunately, only half/51.4\%/of the respondents do so, $31.8 \%$ of respondents not often and sometimes follow a proper diet and $16.8 \%$ do not follow a diet. For the latter, the reasons are: Financial restrictions, poor quality food, limited access to specialty stores for certain food groups.

\section{Conclusions}

- Statistically significant relation was found: $p=0.001$ and $x 2=21.886$. The respondents with two chronic diseases $-40.5 \%$ are well aware of the normal values of the measured indicators

Two-thirds of the respondents/74.3\%/are well informed about the normal and pathological values of the main vital indicators, which they can measure and register themselves

$76 \%$ of the respondents received the requested health information from the medical team, who directly took care of them/model of partnership as part of health education

- Only half of the older respondents in the study $/ 51.4 \% /$ follow a diet complied with their health status.

\section{Conclusions}

In our professional medical care for the elderly people in Bulgaria, we must place emphasis on their preventive and prophylactic commitment to their own health. The useful and practical combination of properly received and internalized medical information from the elderly people is an important prerequisite for their informed commitment to their own health. Their responsible behavior and actions to preserve and strengthen their health are the basis for their future quality of life and self-management.

\section{References}

1. Available from: https://www.nsi.bg/sites/default/files/files/ publications/Zdraveopazvane_2019.pdf. [Last accessed on $2020 \mathrm{Jul}$ 02]

2. Available from: https://www.nsi.bg/sites/default/files/files/ pressreleases/Population2019_XE8MEZL.pdf. [Last accessed on 2020 Jul 02]

3. Available from: https://www.ec.europa.eu/health/home_en. [Last accessed on 2020 Sep 22]

4. Available from: http://www.eprints.nbu.bg/952/1/Profilaktichna medicine_Profilaktichna_telemedicine.pdf. [Last accessed on 2020 Nov 30$]$ 
5. Paskaleva R, Uzunova A. Role of art therapy for psychoemotional and physical stimulation of the elderly. Res Kinesiol. 2015;43(2):239-41.

6. Paskaleva R, Mratzkova G. Increased Motor Activity for Prevention of Complications in the Elderly with Diabetes. Sofia, Bulgaria: International Scientific Congress "Applied Sports Sciences"; 2019. https://doi.org/10.37393/icass2019/112

7. Peak $\mathrm{HH}$, Kim JJ. Related factors of physical activity in rural elderly chronic disease. J Korean Clin Health Sci. 2014;2(4):247-25.

8. ElbazA, Vicente-Vytopilova P, Tavernier B, Sabia S, Dumurgier J, Mazoyer B, et al. Motor function in the elderly: Evidence for the reserve hypothesis. Neurology. 2013;81(5):417-26. https://doi. org/10.1212/wnl.0b013e31829d8761

\section{PMid:23803317}

9. Available from: http://www.hopkinsmedicine.org/health/ cavegiving/types-of-home-health-care-services. [Last accessed on 2020 Sep 15]

10. Available from: http://www.getreferralmd.com/2013/12/will-5technologies-boost-medication-adherence.[Last accessed on 2020 Sep 15]

11. Available from: http://www.getreferralmd.com/2013/12/will-5technologies-boost-medication-adherence. [Last accessed on 2020 Sep 10] 